\title{
PENGARUH BIAYA PEMASARAN TERHADAP PENDAPATAN USAHA DAGANG KUNYIT (Curcuma domestica, Val) DI KECAMATAN PEUREULAK KABUPATEN ACEH TIMUR
}

\author{
Rini Mastuti, SP, MP ${ }^{1} /$ Zulkarnaini $^{2}$ \\ ${ }^{1}$ Dosen Tetap Program Studi Agribisnis Fakultas Pertanian \\ ${ }^{2}$ Mahasiswa Fakultas Pertanian Program Studi Agribisnis \\ Universitas Samudra, Langsa-Aceh
}

Penelitian ini bertujuan untuk mengetahui pengaruh biaya bongkar muat dan biaya pengangkutan terhadap pendapatan usaha dagang kunyit di Kecamatan Peureulak Kabupaten Aceh Timur. Penelitian ini dilaksanakan di Desa Blang Simpo, Desa Blang Bitra, Desa Cot Gulumpang, Desa Paya Meuligou, dan Desa Tanah Rata dalam wilayah Kecamatan Peureulak Kabupaten Aceh Timur dengan menggunakan metode survey dan penentuan daerah sampel dilakukan dengan teknik Sensus (semua populasi) sehingga dipilih desa-desa tersebut sebagai daerah sampel. Hasil perhitungan Analisis Regresi Linear berganda antara biaya bongkar muat $\left(\mathrm{X}_{1}\right)$ dan biaya pengangkutan $\left(\mathrm{X}_{2}\right)$ terhadap pendapatan $(\mathrm{Y})$ usaha dagang kunyit diperoleh persamaan regresi sebagai berikut: $Y=-929,84+3,57 X_{1}+3,12 X_{2}$

Dari persamaan di atas dapat diambil kesimpulan bahwa, setiap penambahan biaya bongkar muat $\left(X_{1}\right)$ maka pendapatan akan bertambah sebesar Rp. 3.570.000,00 dimana $\left(X_{1}\right)$ dianggap tetap. Begitu juga dengan penambahan biaya pengangkutan $\left(\mathrm{X}_{2}\right)$ akan bertambah pendapatan sebesar Rp. 3.120.000,00, dimana $\mathrm{X}_{1}$ dianggap tetap.

\section{PENDAHULUAN}

\section{Latar Belakang}

Pengusaha dalam menjalankan usahanya pasti mengharapkan pendapatan atau keuntungan, dalam prinsip ekonomi dengan biaya yang sekecil mungkin untuk mendapatkan pendapatan sebesar mungkin, yang berarti ingin mendapatkan keuntungan atau pendapatan yang setinggitingginya dari kegiatan usahanya.
Kecamatan Peureulak merupakan salah satu Kecamatan penghasil kunyit di Kabupaten Aceh Timur. Untuk mengetahui perkembangan luas tanam, luas panen, produksi dan produktivitas usahatani kunyit di Kecamatan Peureulak mulai tahun 2009-2013 dapat dilihat pada tabel I - 1 berikut ini.

Tabel I - 1. Perkembangan Luas Tanam, Luas Panen, Produksi dan Produktivitas Usahatani Kunyit di Kecamatan Peureulak Mulai 2009-2013.

\begin{tabular}{|l|l|l|l|l|l|}
\hline $\begin{array}{l}\text { No } \\
\cdot\end{array}$ & Tahun & $\begin{array}{c}\text { Luas } \\
\text { Tanam } \\
(\mathrm{Ha})\end{array}$ & $\begin{array}{c}\text { Luas } \\
\text { Panen } \\
(\mathrm{Ha})\end{array}$ & $\begin{array}{l}\text { Produksi } \\
\text { (Ton) }\end{array}$ & $\begin{array}{l}\text { Produktivitas } \\
\text { (Ton/Ha) }\end{array}$ \\
\hline 1. & 2009 & 15,00 & 15,00 & 225,00 & 15,00 \\
2. & 2010 & 17,50 & 17,50 & 265,00 & 15,14 \\
3. & 2011 & 20,00 & 20,00 & 304,00 & 15,20 \\
4. & 2012 & 22,50 & 22,50 & 350,00 & 15,56 \\
5. & 2013 & 25,50 & 25,50 & 408,00 & 16,00 \\
\hline & Jumlah & 100,50 & 100,50 & $1.552,00$ & 76,90 \\
\hline & Rata-rata & 20,10 & 20,10 & 310,40 & 15,38 \\
\hline
\end{tabular}

Sumber : Dinas Pertanian Tanaman Pangan dan Hortikultura Kabupaten Aceh Timur, 2014. 
Dari tabel I - 1 di atas dapat dilihat bahwa luas tanam, luas panen, produksi dan produktivitas tanaman kunyit di Kecamatan Peureulak Kabupaten Aceh Timur terus mengalami peningkatan dari tahun ke tahun. Hal ini disebabkan dari animo masyarakat yang begitu tinggi untuk berusahatani kunyit, mungkin disebabkan oleh tingkat harga yang diterima petani mendorong petani lainnya untuk ikut berusahatani kunyit pada musim tanam berikutnya.

Kunyit yang dihasilkan petani dapat dijadikan peluang bagi pedagang untuk dapat mengahasilkan pendapatan melalui kegiatan perdagangan kunyit atau membeli kunyit petani untuk dijual kembali ke pedagang besar baik yang ada di dalam daerah maupun keluar daerah. Melalui transaksi inilah pedagang mendapatkan pendapatan, dan petani juga diuntungkan dengan cepatnya kunyit tersebut dibeli oleh pedagang dan dapat juga merangsang petani untuk memperluas areal tanamnya.

Pedagang kunyit berharap usahanya terus berkembang untuk masa yang akan datang, karena usahatani kunyit setiap tahunnya terus bertambah sehingga berpengaruh terhadap aktivitas bisnis yang dijalankan oleh pedagang kunyit. Pedagang dalam memainkan peran dalam membeli kunyit harus memberikan pelayanan yang baik kepada petani, supaya kunyit yang dimiliki petani dapat ditampung dengan mudah oleh pedagang. Oleh karenanya pedagang harus membeli dengan harga yang bersaing dengan pedagang lainnya dalam membeli kunyit, sehingga biaya bongkar muat dan biaya pengangkutan dapat dihitung dengan sebaik mungkin oleh pedagang dalam meningkatkan pendapatannya. Dengan meningkatnya pendapatan pedagang, tentu akan berdampak pada aktivitas lainya yang mendorong pedagang untuk menampung kunyit petani yang lebih banyak untuk masa mendatang dengan harga yang bersaing dan memberikan pendapatan yang setimpal bagi pedagang. Pedagang merasa kesulitan untuk mengetahui pendapatan yang diterima dari usahanya, walaupun secara manual pedagang dapat mengetahui berapa keuntungan atau pendapatan yang bisa diperoleh dari usahanya tersebut. Dengan lancarnya usaha dagang kunyit maka dapat mendorong petani untuk terus berusahatani kunyit ke arah yang lebih untuk masa yang akan datang.

\section{Identifikasi Masalah}

Permasalahan dalam penelitian ini, apakah ada pengaruh biaya bongkar muat dan biaya pengangkutan terhadap pendapatan usaha dagang kunyit di daerah penelitian.

\section{Tujuan Penelitian}

Tujuan penelitian ini adalah untuk mengetahui pengaruh biaya bongkar muat dan biaya pengangkutan terhadap pendapatan usaha dagang kunyit di daerah penelitian.

\section{METODOLOGI PENELITIAN Lokasi, Objek, Ruang Lingkup dan Waktu Penelitian}

Metode yang digunakan dalam penelitian ini adalah metode survey. Nazir (2005:550), Lokasi penelitian dilaksanakan di Kecamatan Peureulak Kabupaten Aceh Timur dengan pertimbangan bahwa kecamatan tersebut merupakan daerah yang terdapat usaha dagang kunyit.

Objek penelitian ini hanya dibatasi pada pedagang yang melakukan pembelian kunyit di Kecamatan Peureulak Kabupaten Aceh Timur. Ruang lingkup penelitian ini dibatasi pada biaya pembelian, biaya pemasaran, tenaga kerja dan nilai penjualan di Kecamatan Peureulak Kabupaten Aceh Timur.

\section{Teknik Penentuan Sampel dan Pengumpulan Data Penentuan Sampel}

Pengambilan pedagang sampel dilakukan dengan menggunakan metode 
Sensus yaitu semua populasi yang tersedia semuanya dijadikan sampel. Untuk lebih jelasnya mengenai jumlah populasi dan 2014.

pedagang sampel di daerah penelitian dapat dilihaat pada tabel II-1 berikut.

\begin{tabular}{|l|l|c|c|}
\hline No. & Nama Sampel/Alamat & $\begin{array}{c}\text { Jumlah Populasi } \\
\text { (Unit Usaha) }\end{array}$ & $\begin{array}{c}\text { Jumlah Sampel } \\
\text { (Unit Usaha) }\end{array}$ \\
\hline 1. & Safrijal/Blang Simpo & 1 & 1 \\
2. & Ishak/Blang Simpo & 1 & 1 \\
3. & Ilyas/Blang Simpo & 1 & 1 \\
4. & Burhan/Blang Bitra & 1 & 1 \\
5. & M. Yusuf Umar/Cot Gulumpang & 1 & 1 \\
6. & Anwar/Paya Meuligou & 1 & 1 \\
7. & Kaprawi/Paya Meuligou & 1 & 1 \\
8. & Jamal/Paya Meuligou & 1 & 1 \\
9. & M. Yusuf/Paya meuligou & 1 & 1 \\
10. & Rusli/Paya Meuligou & 1 & 1 \\
11. & Ismail/Tanah Rata & 1 & 12 \\
12. & & 1 & 12 \\
\hline \multicolumn{2}{|l}{ J u m l a h } & 1 \\
\hline
\end{tabular}

Sumber : Data Primer, 2014 (diolah).

Pada tabel II-1 di atas dapat dilihat bahwa jumlah pedagang seluruhnya 12 orang, sedangkan jumlah pedagang sampel juga sebanyak 12 unit usaha (orang), dengan perincian seperti terlihat pada tabel II-1 di atas.

\section{Pengumpulan Data}

Data yang dikumpulkan dalam penelitian ini dapat berupa data primer maupun data sekunder. "Data primer dalam penelitian ini dapat diperoleh dari petani responden dengan cara melakukan wawancara langsung dengan petani responden dengan bantuan daftar pertanyaan (kuesioner) yang telah dipersiapkan sebelumnya. Menurut Kountur (2008:63)," data primer adalah data yang dikumpulkan peneliti langsung dari sumbernya".

Menurut Teguh, (2005:121), " data sekunder adalah jenis data yang diperoleh dan digali melalui hasil pengolahan pihak kedua dari hasil penelitian lapangannya, baik berupa data kualitatif maupun data kuantitatif: Jenis data ini sering juga disebut data eksternal". Data sekunder diperoleh dari instansi terkait baik instansi Pemerintah Kabupaten, Kecamatan, Desa maupun Perpustakaan untuk mendapatkan literatur-literatur yang ada kaitannya dengan penelitian ini.

Variabel data yang dianalisis dalam penelitian ini terdiri dari :
a. Luas Tempat Usaha $\left(\mathrm{M}^{3}\right)$
b. Biaya operasional (Rp/Tahun)
c. Biaya pemasaran (Rp/Tahun)
d. Pendapatan (Rp/Tahun)
e. Penggunaan Tenaga Kerja
(HKP/Tahun).

\section{Metode Analisis dan Pengujian Hipotesis}

a. Analisis Data

Data yang telah dikumpulkan di lapangan diolah dan dipindahkan ke dalam bentuk tabulasi, yang selanjutnya 
dipindahkan lagi ke dalam bentuk tabelaris sesuai dengan kebutuhan analisis.

b. Pengujian Hipotesis

Hipotesis yang telah dirumuskan di atas akan diuji kebenarannya dengan menggunakan analisis regresi linear berganda, dengan satu variabel dependen (Y) dan dua variabel independen yaitu variabel $\left(X_{1}\right.$, dan $\left.X_{2}\right)$ dengan persamaan regresinya sebagai berikut :

$Y^{\prime}=a+b_{1} X_{1}+b_{2} X_{2}$

$\mathrm{Y}=$ Pendapatan (Rp/Tahun)

$\mathrm{X}_{1}=$ Biaya Bongkar Muat (Rp/Tahun)

$\mathrm{X}_{2}=$ Biaya Pengangkutan (Rp/Tahun)

$\mathrm{a}, \mathrm{b}_{1}$, dan $\mathrm{b}_{2}$ adalah parameter yang dicari.

\section{Dengan Kaedah Keputusan :}

Apabila $\mathrm{F}_{\text {cari }}>\mathrm{F}_{\text {tabel, }}$ maka terima $\mathrm{H}_{\mathrm{a}}$ dan tolak $\mathrm{H}_{\mathrm{o}}$, yang berarti secara serempak variabel $X_{1}$, dan $X_{2}$ berpengaruh terhadap variabel $\mathrm{Y}$.

Apabila $\mathrm{F}_{\text {cari }} \leq \mathrm{F}_{\text {tabel, }}$ maka terima $\mathrm{H}_{\mathrm{o}}$ dan tolak $\mathrm{H}_{\mathrm{a}}$, yang berarti secara serempak variabel $\mathrm{X}_{1}$, dan $\mathrm{X}_{2}$ tidak berpengaruh terhadap variabel $\mathrm{Y}$.

Begitu juga halnya terhadap uji " $t$ " :

Apabila $\mathrm{t}_{\text {cari }}>\mathrm{t}_{\text {tabel, }}$ maka terima $\mathrm{H}_{\mathrm{a}}$ dan tolak $\mathrm{H}_{0}$, yang berarti secara parsial variabel $X_{1}$, dan $X_{2}$ berpengaruh terhadap variabel $Y$.

\section{HASIL PENELITIAN DAN PEMBAHASAN \\ Karakteristik Pedagang}

Untuk lebih jelasnya mengenai karakteristik pedagang dalam usaha dagang kunyit di daerah penelitian dapat dilihat pada tabel IV.1 berikut ini :

Tabel IV-1 : Karakteristik Pedagang Kunyit di Daerah Penelitian 2014.

\begin{tabular}{|c|c|c|c|c|c|}
\hline No. & Nama Sampel & $\begin{array}{l}\text { Umur } \\
\text { ( tahun) }\end{array}$ & $\begin{array}{l}\text { Pendidikan } \\
\text { (tahun) }\end{array}$ & $\begin{array}{l}\text { Pengalaman } \\
\text { (tahun) }\end{array}$ & $\begin{array}{l}\text { Tanggungan } \\
\text { (orang) }\end{array}$ \\
\hline 1. & Safrizal & 45 & 9 & 15 & 6 \\
\hline 2. & Ishak & 40 & 12 & 10 & 5 \\
\hline 3. & $\begin{array}{l}\text { Illyas } \\
\text { Burhan }\end{array}$ & 42 & 9 & 12 & 6 \\
\hline 4. & M. Yusuf Umar & 40 & 12 & 12 & 5 \\
\hline 5. & Anwar & 39 & 12 & 9 & 6 \\
\hline 6. & $\begin{array}{l}\text { Kaprawi } \\
\text { Nurdin }\end{array}$ & 42 & 12 & 12 & 5 \\
\hline 7. & Jamal & 43 & 12 & 13 & 6 \\
\hline 8. & Rusli & 37 & 12 & 7 & 6 \\
\hline 9. & Ismail & 42 & 9 & 12 & 5 \\
\hline 10. & & 40 & 12 & 12 & 5 \\
\hline 11. & & 46 & 9 & 15 & 4 \\
\hline 12. & & 40 & 12 & 10 & 5 \\
\hline & Rata-rata & 41,33 & 10,91 & 11,58 & 5,00 \\
\hline
\end{tabular}

Sumber : Lampiran IV-1.

Dari tabel IV-1 dapat dilihat bahwa ratarata umur pedagang di daerah penelitian adalah 41,33 tahun dengan tingkat pendidikan rata-rata 10,91 tahun (rata-rata tamat SMP). Sedangkan pengalaman di bidang usaha dagang kunyit rata-rata 11,58 tahun, dengan jumlah tanggungan keluarga rata-rata 5,00 orang. 


\section{Penggunaan Tenaga Kerja}

Dalam pengertian ekonomi, tenaga kerja merupakan sumber daya manusia yang digunakan untuk melakukan suatu usaha dengan tujuan dapat menghasilkan pendapatan. Tenaga kerja merupakan salah satu dari faktor produksi yang sangat penting dalam usaha dagang atau usaha-usaha lain. Penggunaan tenaga kerja yang efektif dan efisien dapat mempengaruhi biaya produksi yang akan dikeluarkan. Tenaga kerja yang digunakan pada usaha dagang kunyit pada desa sampel berasal dari tenaga kerja dalam keluarga dan luar keluarga yang terdiri dari pria, wanita dan anak-anak.

Adapun jenis kegiatan yang dilakukan dalam pengelolaan usaha dagang kunyit di daerah penelitian meliputi pembukaan kios, penimbangan, penyortiran, penggonian dan bongkar muat.

Untuk menghitung besarnya pencurahan tenaga kerja dari setiap jenis tenaga kerja yang digunakan seluruhnya dikonversikan ke dalam Hari Kerja Pria (HKP). Dengan berdasarkan upah yang berlaku pada saat penelitian, dimana satu HKP diartikan seorang tenaga kerja yang bekerja 6 jam rata-rata perhari atau dengan upah dibayarkan sebesar Rp. 50.000/hari kerja. Besarnya upah yang diterima oleh masing-masing tenaga kerja pada usaha dagang kunyit sangat tergantung dari besarnya pencurahan tenaga kerja yang bersangkutan selama proses berlangsung. Untuk lebih jelasnya rata-rata penggunaan tenaga kerja per pedagang dan per tahun pada berbagai jenis/fase kegiatan usaha dagang kunyit dapat dilihat pada tabel IV-2 berikut ini.

Tabel IV-2 : Rata-rata Penggunaan Tenaga Kerja Per Tahun Pada Berbagai Fase Kegiatan Usaha Dagang Kunyit di Daerah Penelitian 2014

\begin{tabular}{|c|c|c|c|c|}
\hline \multirow{2}{*}{ No } & \multirow{2}{*}{ Jenis Kegiatan } & \multicolumn{2}{|c|}{$\begin{array}{l}\text { Penggunaan } \\
\text { Tenaga Kerja/Tahun } \\
\text { (HKP) }\end{array}$} & \multirow{2}{*}{$\begin{array}{l}\text { Jumlah } \\
\text { (HKP) }\end{array}$} \\
\hline & & DK & LK & \\
\hline 1 & Pembukaan Kios & 13,40 & 7,12 & 20,52 \\
\hline 2 & Penimbangan & 16,83 & 8,63 & 25,46 \\
\hline 3 & Penyortiran & 11,36 & 7,73 & 19,09 \\
\hline 4 & Penggonian & 11,61 & 7,82 & 19,43 \\
\hline 5 & Bongkar Muat & 19,72 & 33,58 & 53,30 \\
\hline & Jumlah & 72,92 & 64,87 & 137,78 \\
\hline
\end{tabular}

Sumber : Lampiran IV-2.

Ket $\quad$ DK $=$ Dalam Keluarga

LK = Luar Keluarga

Tabel di atas memperlihatkan bahwa penggunaan tenaga kerja tiap fase kegiatan pada usaha dagang kunyit bervariasi. Hal Ini disebabkan karena penggunaan tenaga kerja tersebut dipakai sesuai dengan kebutuhan. Pemakaian tenaga kerja paling besar terdapat pada fase kegiatan bongkar muat yaitu sebesar

53,30 HKP/tahun (19,72 HKP dalam keluarga) dan (33,58 HKP luar keluarga). Sedangkan penggunaan tenaga kerja yang terkecil terdapat pada fase penyortiran yaitu sebesar 19,09 HKP/tahun (11,36 HKP dalam keluarga) dan (7,73 HKP luar keluarga). Untuk lebih jelasnya mengenai penggunaan tenaga kerja pada berbagai fase 
kegiatan tersebut dapat dilihat pada lampiran IV -1 .

Rata-rata penggunaan tenaga kerja per pedagang sampel pada usaha dagang kunyit di daerah penelitian dapat dilihat pada tabel IV-3 berikut ini.

Tabel IV- 3. Rata-Rata Penggunaan Tenaga Kerja Per Usaha Dagang Kunyit di Daerah Penelitian 2014.

\begin{tabular}{|c|c|c|}
\hline No. & Nama Sampel & $\begin{array}{l}\text { Penggunaan tenaga Kerja } \\
\text { ( HKP/tahun) }\end{array}$ \\
\hline 1. & Safrizal & 147,70 \\
\hline 2. & Ishak & 153,10 \\
\hline 3. & Illyas & 140,80 \\
\hline 4. & Burhan & 138,30 \\
\hline 5. & M. Yusuf Umar & 135,60 \\
\hline 6. & Anwar & 121,60 \\
\hline 7. & $\begin{array}{l}\text { Kapraw1 } \\
\text { Nurdin }\end{array}$ & 130,90 \\
\hline 8. & Jamal & 142,70 \\
\hline 9. & M. Yusuf & 142,70 \\
\hline 10. & Rusli & 133,60 \\
\hline 11. & Ismail & 132,90 \\
\hline 12. & & 133,50 \\
\hline & Rata-rata & 137,78 \\
\hline
\end{tabular}

Sumber : Lampiran IV-2.

Tabel IV-4 di atas dapat dilihat bahwa rata-

terdiri dari biaya pembelian kunyit, rata penggunan tenaga kerja per pedagang adalah 137,78 HKP. Penggunaan tenaga kerja terbesar terdapat pada sampel Ishak yaitu 153,10 HKP per tahun. Sedangkan penggunaan tenaga kerja yang terkecil terdapat pada sampel Anwar yaitu 121,60 HKP per tahun.

Dari tabel di atas dapat dilihat bahwa biaya tetap yang harus dikeluarkan oleh pedagang adalah Rp.661.680,56 per pedagang per konsumsi, pulsa Hp, listrik, air, pengangkutan dan tenaga kerja. Dari biaya tersebut yang merupakan penggunaan biaya produksi terbesar pada usaha dagang kunyit adalah terletak pada biaya pembelian kunyit yaitu sebesar Rp 176.250.000,00 per tahun.

Untuk lebih jelasnya dapat dilihat pada tabel IV-5 berikut ini :

tahun. Sedangkan pada biaya variabel

Tabel IV-5 : Rata-rata Pendapatan Pedagang Per Tahun Pada Usaha Dagang Kunyit Di Daerah Penelitian 2014.

\begin{tabular}{|l|l|c|l|}
\hline No & Uraian & Satuan & Rata-rata/Tahun \\
\hline 1 & Pembelian Kunyit & $\mathrm{Kg}$ & $117.500,00$ \\
\hline 2 & Nilai Penjualan & $\mathrm{Rp}$ & $423.000 .000,00$ \\
\hline 3 & Biaya Produksi & $\mathrm{Rp}$ & $238.032 .097,22$ \\
\hline 4 & Pendapatan & $\mathrm{Rp}$ & $184.967 .902,78$ \\
\hline
\end{tabular}

Sumber: Lampiran IV-6. 
Tabel di atas menunjukkan bahwa rata-rata pendapatan usaha dagang kunyit yaitu sebesar Rp.184.967.902,78 per tahun. Untuk lebih jelasnya dapat dilihat pada lampiran IV-5.

\section{Pengaruh Biaya Bongkar Muat dan Biaya Pengangkutan terhadap Pendapatan Usaha Dagang Kunyit}

Faktor biaya bongkar muat dan biaya pengangkutan sangat mempengaruhi terhadap pendapatan usahatani. Namun kenyataan ini tidak dapat diterima begitu saja tanpa adanya pembuktian atau perhitungan-perhitungan secara ilmiah melalui kegiatan-kegiatan penelitian.

Untuk mengetahui pengaruh faktor biaya bongkar muat dan biaya pengangkutan terhadap pendapatan usaha dagang, diuji dengan menggunakan model persamaan regresi linear berganda, dengan formula : $Y^{\prime}=a+b_{1} X_{1}+b_{2} X_{2}$

Dari hasil perhitungan regresi linear berganda antara biaya bongkar muat $\left(\mathrm{X}_{1}\right)$ dan biaya pengangkutan $\left(\mathrm{X}_{2}\right)$ terhadap pendapatan diperoleh persamaan regresi sebagai berikut :

$Y^{\prime}=-929,84+3,57 X_{1}+3,12 X_{2}$

Dari persamaan di atas menunjukkan adanya pengaruh antara biaya bongkar muat $\left(\mathrm{X}_{1}\right)$ dan biaya pengangkutan $\left(\mathrm{X}_{2}\right)$ terhadap pendapatan (Y) usaha dagang, dimana setiap penambahan biaya bongkar muat, maka pendapatan akan naik sebesar Rp. $\quad 3.570 .000,00$ jika biaya pengangkutan $\left(\mathrm{X}_{2}\right)$ tetap. Begitu juga sebaliknya setiap penambahan biaya pengangkutan $\left(\mathrm{X}_{2}\right)$ maka pendapatan akan naik sebesar Rp. 3.120.000,00 jika biaya bongkar muat $\left(\mathrm{X}_{1}\right)$ tetap. Untuk melihat apakah koefisien dari regresi mempunyai pengaruh nyata atau tidak dilakukan pengujian dengan menggunakan uji " $t$ " secara partial dan uji "F" secara serempak. Dari hasil pengujian secara serempak yang dilakukan dengan uji "F" pada fungsi regresi linear berganda, diperoleh $\mathrm{F}_{\text {cari }}$ sebesar 8,38 dan $F_{\text {tabel }}$ pada tingkat kepercayaan $95 \%$ dan $99 \%$, yaitu sebesar
4,26 dan 8,02. Dengan kata lain $F_{\text {cari }}$ $>F_{\text {tabel}}$, ini berarti bahwa pendapatan usaha dagang berpengaruh secara nyata oleh biaya bongkar muat $\left(\mathrm{X}_{1}\right)$ dan biaya pengangkutan $\left(\mathrm{X}_{2}\right)$. Maka dengan demikian hipotesis yang menyatakan bahwa besarnya biaya bongkar muat $\left(\mathrm{X}_{1}\right)$ dan biaya pengangkutan $\left(\mathrm{X}_{2}\right)$ mempunyai pengaruh yang sangat nyata terhadap pendapatan usaha dagang, sehingga hipotesis menolak Ho dan menerima Ha.

Dari hasil uji "t" secara partial, ternyata dari uji tersebut masing-masing nilai $t_{\text {cari }}$ $\mathrm{X}_{1}$ dan $\mathrm{X}_{2}$ adalah 0,137 dan 2,400 dan $t_{\text {tabel }}$ pada tingkat kepercayaan $95 \%$ adalah sebesar 2,262. Dengan kata lain $\mathrm{t}_{\text {cari }} \mathrm{X}_{1}<\mathrm{t}_{\text {tabel}}$, untuk variabel $\mathrm{X}_{1}$, yang berarti biaya bongkar muat $\left(\mathrm{X}_{1}\right)$ tidak berpengaruh secara nyata terhadap pendapatan pedagang, jika $\mathrm{X}_{2}$ tetap, maka Ho diterima dan Ha ditolak, begitu juga sebaliknya $t_{\text {cari }} X_{2}>t_{\text {tabel }}$ untuk variabel $\mathrm{X}_{2}$ yang berarti biaya pengangkutan $\left(\mathrm{X}_{2}\right)$ berpengaruh secara nyata terhadap pendapatan pedagang, maka Ha diterima dan Ho ditolak. Kemudian untuk melihat tingkat keeratan hubungan antara biaya bongkar muat $\left(\mathrm{X}_{1}\right)$ dan biaya pengangkutan $\left(\mathrm{X}_{2}\right)$, dapat dianalisis dengan menggunakan koefisien Determinasi $\quad\left(\mathrm{R}^{2}\right)$. Dari hasil perhitungan koefisien determinasi menunjukkan bahwa besarnya $\mathrm{R}^{2}=$ 0,6503 . Ini berarti bahwa sebesar $65,03 \%$ dapat dijelaskan oleh variabel $\mathrm{X}_{1}$ dan $\mathrm{X}_{2}$ terhadap variabel $(\mathrm{Y})$, sedangkan sisanya $34,97 \%$, dipengaruhi oleh variabel lain yang tidak ikut diteliti dalam penelitian ini.

\section{KESIMPULAN DAN SARAN}

\section{Kesimpulan}

1. Hasil pengujian pengaruh biaya bongkar muat $\left(\mathrm{X}_{1}\right)$ dan biaya pengangkutan $\left(\left(\mathrm{X}_{2}\right)\right.$ terhadap pendapatan usaha dagang kunyit diperoleh koefisien determinasi sebesar $\mathrm{R}^{2}=0,6503$ atau $65,03 \%$, yang berarti besarnya sumbangan 
(andil) biaya bongkar muat $\left(\mathrm{X}_{1}\right)$ dan biaya pengangkutan $\left(\mathrm{X}_{2}\right)$ terhadap pendapatan (Y) sebesar $\quad 65,03 \%$ sedangkan sisanya $34,97 \%$ dipengaruhi oleh variabel lainnya yang tidak ikut diteliti dalam penelitian ini.

2. Berdasarkan hasil uji secara partial dari fungsi linear berganda menunjukkan bahwa variabel biaya bongkar muat $\left(\mathrm{X}_{1}\right)$ diperoleh $\mathrm{t}_{\text {cari }}<\mathrm{t}_{\text {tabel }}$ atau 0,137 $<2,262$ pada taraf kepercayaan $95 \%$, yang berarti bahwa pendapatan usahadagang kunyit tidak berpengaruh nyata oleh biaya bongkar muat. Sedangkan variabel biaya pengangkutan $\left(\mathrm{X}_{2}\right)$ diperoleh $t_{\text {cari }}>t_{\text {tabel }}$ atau 2,400> 2,262 pada taraf kepercayaan $95 \%$, yang berarti bahwa pendapatan usaha dagang kunyit berpengaruh nyata oleh biaya pengangkutan $\left(\mathrm{X}_{2}\right)$.

\section{Saran-saran}

1. Dalam usaha untuk meningkatkan pendapatan pedagang pada usaha dagang kunyit dapat dilakukan dengan jalan memperbesar biaya bongkar muat dan biaya pengangkutan, karena berdasarkan uji secara serempak menunjukkan bahwa koefisien biaya bongkar muat dan biaya pengankutan berkorelasi positif dan berpengaruh sangat nyata terhadap pendapatan.

2. Diharapkan kepada pemerintah dalam hal ini instansi terkait (Dinas Perdagangan) untuk terus memberikan penyuluhan dan bimbingan terutama menyangkut informasi pasar terhadap produk kunyit dan masukan yang berguna bagi pengembangan usaha dagang kunyit di masa mendatang.

DAFTAR PUSTAKA

Basu Swastha, 2004. Pengantar Bisnis Modern, Media Pressindo, Yogyakarta. Deden, 2003. Analisis Biaya Pemasaran, Online, Diakses Tanggal 1 Juli 2014.

Kountur, 2008. Menguasai Riset Pemasaran, Cara Mudah dan Praktis, PPM, Jakarta.

Mardikanto, 2009. Membangun Pertanian Modern, UNS-Press, Surakarta Jawa Tengah.

Marwan, 1991. Metode Penjualan, Online, Diakses Tanggal 1 Juli 2014.

Mubyarto dan Suratno, 1981. Metodologi Penelitian Ekonomi, $\quad$ Yayasan Agronomika, Yogyakarta.

Nazir, M, 2005. Metode Penelitian, Ghalia Indonesia, Bogor. Nopirin, 2008. Ekonomika Mikro, Tarsito, Bandung. Rukmana, 1994. Budidaya Kunyit, Bumi Aksara, Jakarta.

Slamet, 2006. Pengantar Penelitian Kuantitatif, UNS Press, Surakarta. Sudjana, 1983. Teknik Analisis Regresi dan Korelasi, Tarsito, Bandung. Sugiono, 2009. Metode Penelitian Bisnis, UI Press, Jakarta.

Sudayat, 2012. Pengertian Penjualan, Omline, Diakses Tanggal 1 Juli 2014. Soetrisno, 2006. Pengantar Ilmu Pertanian. Bayumedia, Malang.

Teguh, 2005. Metodologi Penelitian Ekonomi Teori dan Aplikasi. Rajawali Pers, Jakarta. 